\title{
A Conventional Liner Acoustic/Drag Interaction Benchmark Database
}

\author{
Brian M. Howerton $^{1}$ and Michael G. Jones. ${ }^{2}$ \\ NASA Langley Research Center, Hampton, VA, 23681
}

\begin{abstract}
The aerodynamic drag of acoustic liners has become a significant topic in the design of such for aircraft noise applications. In order to evaluate the benefits of concepts designed to reduce liner drag, it is necessary to establish the baseline performance of liners employing the typical design features of conventional configurations. This paper details a set of experiments in the NASA Langley Grazing Flow Impedance Tube to quantify the relative drag of a number of perforate-over-honeycomb liner configurations at flow speeds of $M=0.3$ and 0.5. These conventional liners are investigated to determine their resistance factors using a static pressure drop approach. Comparison of the resistance factors gives a relative measurement of liner drag. For these same flow conditions, acoustic measurements are performed with tonal excitation from 400 to $3000 \mathrm{~Hz}$ at source sound pressure levels of 140 and $150 \mathrm{~dB}$. Educed impedance and attenuation spectra are used to determine the interaction between acoustic performance and drag.
\end{abstract}

\section{Nomenclature}

$a \quad=$ duct width

$b \quad=$ duct height

$c \quad=$ speed of sound

$d_{h} \quad=$ duct hydraulic diameter

$\gamma \quad=$ ratio of specific heats

$\lambda_{L+S W}=$ resistance factor of the liner plus the hardwall portion of the test section

$\lambda_{L} \quad=$ resistance factor of the liner

$\lambda_{S W} \quad=$ resistance factor of a smooth wall sample

$L \quad=$ length of perforation

$L L \quad=$ liner length

$M \quad=$ centerline flow Mach number

$p_{s \infty} \quad=$ static pressure, absolute

$p \quad=$ static pressure, differential

$P_{a t m}=$ atmospheric pressure

$P \quad=$ perimeter length of the test section

$S=$ static pressure port separation distance

$q \quad=$ dynamic pressure

$W \quad=$ width of perforation

$W_{L} \quad=$ width of liner

$x=$ streamwise duct coordinate

$\rho \quad=$ density

\section{Introduction}

coustic liners have been successfully used for more than four decades to reduce the radiated noise from - turbofan aircraft engines. However, the construction of typical liners has been shown to produce more drag as compared to a smooth surface ${ }^{1}$ as their perforated facesheets create flow disturbances akin to increased surface roughness. Liner drag can also be increased by acoustic excitation as seen by Drouin ${ }^{2}$ and Howerton. ${ }^{3}$ Until recently,

\footnotetext{
${ }^{1}$ Research Scientist, Structural Acoustics Branch, MS 463, Senior Member AIAA, (brian.m.howerton@nasa.gov).

${ }^{2}$ Senior Research Scientist, Structural Acoustics Branch, MS 463, Associate Fellow AIAA.
} 
the aerodynamic drag penalty associated with acoustic liners in an aircraft engine was largely dismissed as necessary to achieve desired noise levels. Renewed focus on reducing aircraft fuel burn has brought interest in characterizing acoustic liner drag and developing strategies to minimize the associated penalties without significant impact to acoustic performance. Several advanced aircraft propulsion concepts (open-rotor, distributed electric) may lead to airframe designs where external liners (Fig. 1) are required to meet community noise goals. ${ }^{4}$ For these applications, liner aerodynamic performance could be crucial to enabling such advanced aircraft configurations.

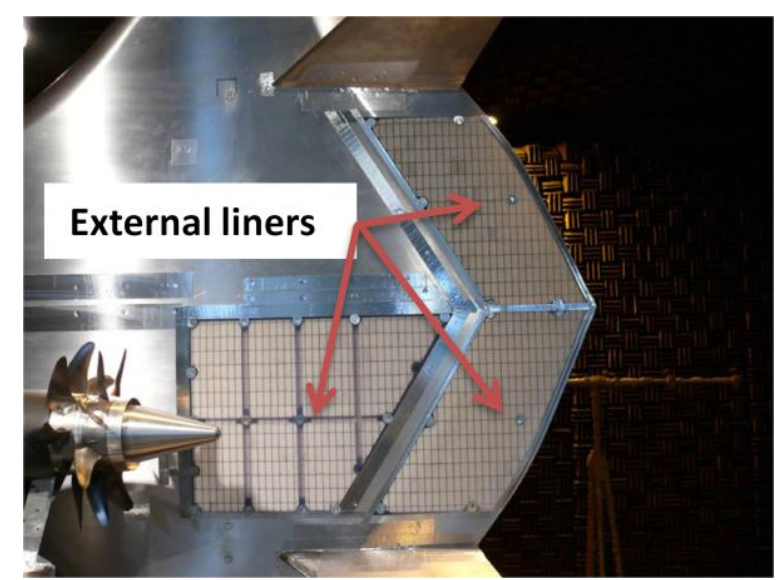

Open-rotor, Blended Wing-Body

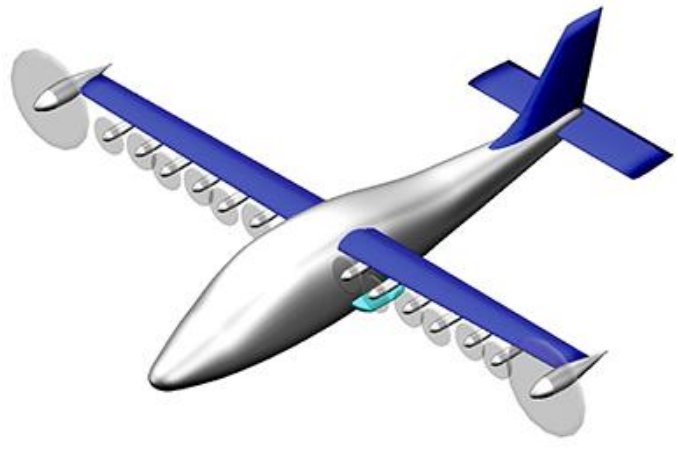

Distributed Electric Propulsion

\section{Figure 1. External liner applications}

NASA is committed to developing a suite of technologies to substantially reduce aircraft fuel consumption and noise. Development of a low-drag acoustic liner would be a significant contribution to that effort. The majority of acoustic liners developed for production aircraft engines use a facesheet perforated with round holes to provide the necessary porosity. These holes provide additional roughness which increases liner drag relative to a smooth surface $^{3}$. An approach from Nikuradse ${ }^{5}$ allows for calculation of a resistance factor $(\lambda)$ based on the static pressure drop within a lined duct. Howerton and Jones ${ }^{6}$ used this approach to show that reducing the perforate hole diameter produced a reduction in $\lambda$ (and thus the drag) for a typical liner design relative to a smooth, hard wall (HW) as shown in Fig. 2.
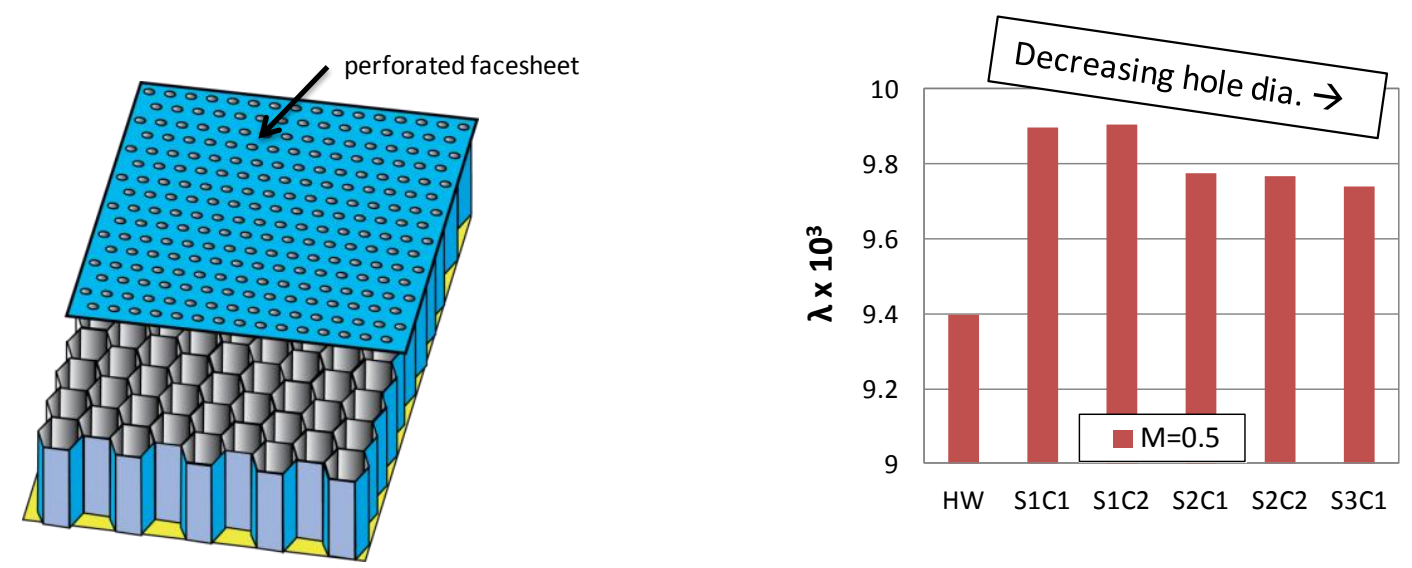

Figure 2. Conventional liner construction and the effect of perforate hole dia. on $\lambda$.

Varying the perforate geometry from the typical round hole can also have an effect on liner drag. Experiments by the authors on a number of perforate shapes and orientations showed significant changes to the measured resistance factor even though the percent open area (POA) remained constant. ${ }^{3}$ The acoustic performance of these liners was 
also measured, which demonstrated that low-drag designs could have impedance and attenuation characteristics comparable to conventional liners.

The purpose of the current investigation is to evaluate a wide variety of conventionally-constructed, acoustic liners for both acoustic performance as well as relative drag. Each liner is tested in the NASA Langley Research Center Grazing Flow Impedance Tube (GFIT), and the resultant acoustic and aerodynamic responses are gathered to (1) provide data for establishing baseline metrics of conventional liner drag and (2) provide a benchmark database of conventional liner drag without acoustic excitation, the interaction of drag and acoustics and a characterization of liner acoustic performance. Such data should be useful in exploring trades between acoustic performance and drag. Details are provided on the static pressure drop method used to compute $\lambda$ along with a description of the liner samples tested. A subset of these results are reported herein. The measured data for the current set of liners, along with analyzed results and a hardwall baseline, is available for public distribution via the authors. The full database of 24 configurations will be released following publication of those results in the near future.

\section{Liner Drag Measurements}

For this investigation, the drag of each configuration relative to a smooth wall will be determined by measuring differences in the static pressure drop along the duct wall opposite of the liner sample. This method can be applied to small ducts with fully-developed, turbulent flow and is similar to Nikuradse's approach when studying roughness in pipes. ${ }^{5,6}$ With the static pressure data and selected flow parameters, one can compute the duct resistance factor, $\lambda$ (also known as the 'friction factor'), given by the following:

$$
\lambda=\frac{d p}{d x} \frac{d_{h}}{q}
$$

using the hydraulic diameter of the flow duct for $\mathrm{d}_{\mathrm{h}}$ :

$$
d_{h}=\frac{2 a b}{a+b}
$$

and the compressible form for q:

$$
q=\frac{\gamma}{2} p_{s \infty} M^{2}
$$

The nondimensional nature of $\lambda$ allows the static pressure data to be normalized, taking out the run-to-run effects of slightly varying duct Mach number and static pressure. Note that $\lambda$ encompasses the sum of both the skin friction and pressure components of drag. Thus, any effects of the liner cavity are also included, thereby differentiating this method from others that are solely measuring skin friction. The results of these calculations can be used to provide a relative measurement of drag between liner configurations.

\section{Experiment}

The experimental investigation involves testing of nine liner and one smooth wall configurations in the GFIT. The construction of these test liners is typical of those used in aircraft engine production. An aluminum smooth wall sample (SW) with no perforations is included to provide a reference baseline. For each configuration, a highaccuracy measurement of the axial static pressure drop across the liner is made to compute the liner resistance factor with and without acoustic excitation. Simultaneously, measurements are made using an array of microphones to characterize the acoustic performance of each liner.

\section{A. Liner Construction}

The design of the liner samples follows a Modern Design of Experiments (MDOE) approach with parameter variation of percent open area (POA), hole diameter, sheet thickness and resistance of a mesh underlayment. Core depth is held constant at $38.1 \mathrm{~mm}$ and a common core construction is employed. Figure 3 provides photographs of a portion of the test liners to show relative variations in hole size and porosity. A summary of the key parameters for each liner is given in Table 1. 

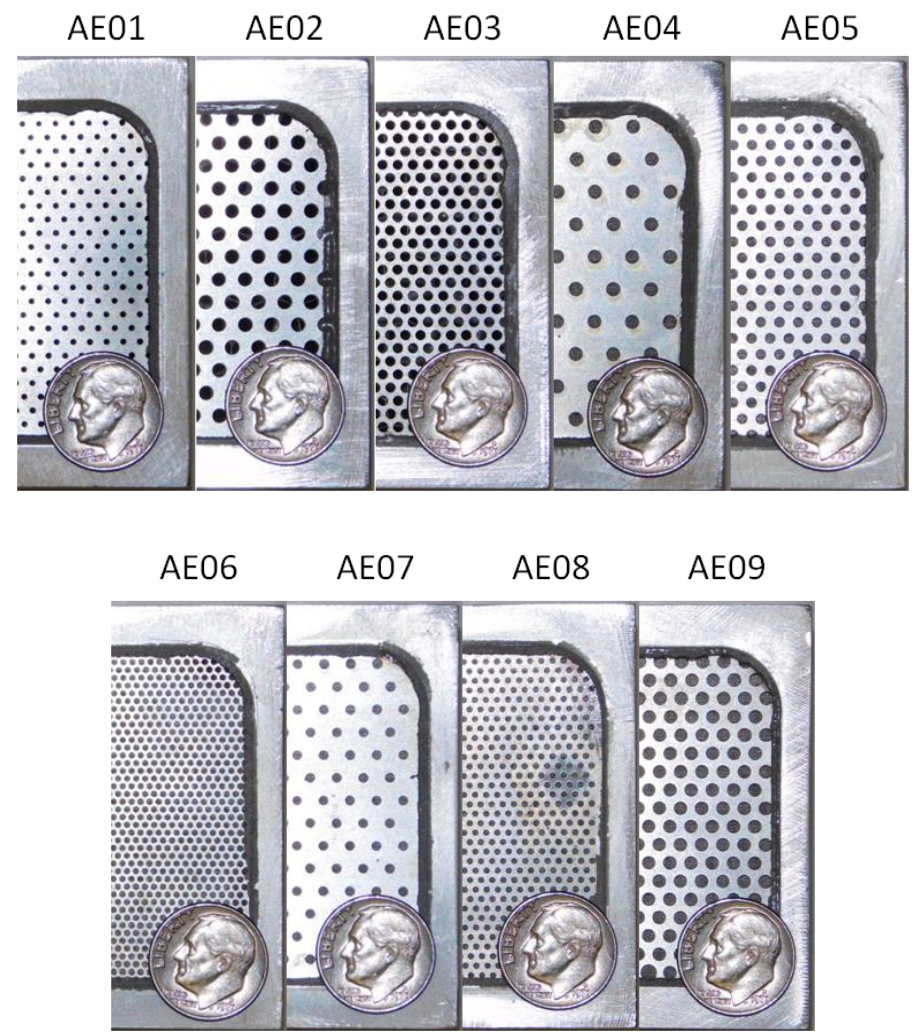

Figure 3. Facesheet perforate geometry.

Table 1. Liner facesheet characteristics.

\begin{tabular}{|c|c|c|c|c|}
\hline Sample & $\begin{array}{c}\text { Perf } \\
\text { POA } \\
(\%)\end{array}$ & $\begin{array}{c}\text { Mesh } \\
\text { MKS } \\
\text { rayls }\end{array}$ & $\begin{array}{c}\text { Hole } \\
\text { Dia. } \\
(\mathbf{m m})\end{array}$ & $\begin{array}{c}\text { Sheet } \\
\text { Thickness } \\
(\mathbf{m m})\end{array}$ \\
\hline AE01 & 10 & $\mathrm{n} / \mathrm{a}$ & 0.762 & 0.762 \\
\hline AE02 & 20 & $\mathrm{n} / \mathrm{a}$ & 1.778 & 1.778 \\
\hline AE03 & 30 & $\mathrm{n} / \mathrm{a}$ & 1.27 & 1.27 \\
\hline AE04 & 10 & 65 & 1.778 & 1.778 \\
\hline AE05 & 20 & 65 & 1.27 & 1.27 \\
\hline AE06 & 30 & 65 & 0.762 & 0.762 \\
\hline AE07 & 10 & 100 & 1.27 & 1.27 \\
\hline AE08 & 20 & 100 & 0.762 & 0.762 \\
\hline AE09 & 30 & 100 & 1.778 & 1.778 \\
\hline
\end{tabular}

4

American Institute of Aeronautics and Astronautics 
Figure 4 provides an exploded view of the liner construction along with a photograph of one of the assembled liners. For all configurations, overall liner length is fixed at $415 \mathrm{~mm}$ with width of $63.5 \mathrm{~mm}$. The sample active area is $406.4 \mathrm{~mm} \times 50.5 \mathrm{~mm}$.
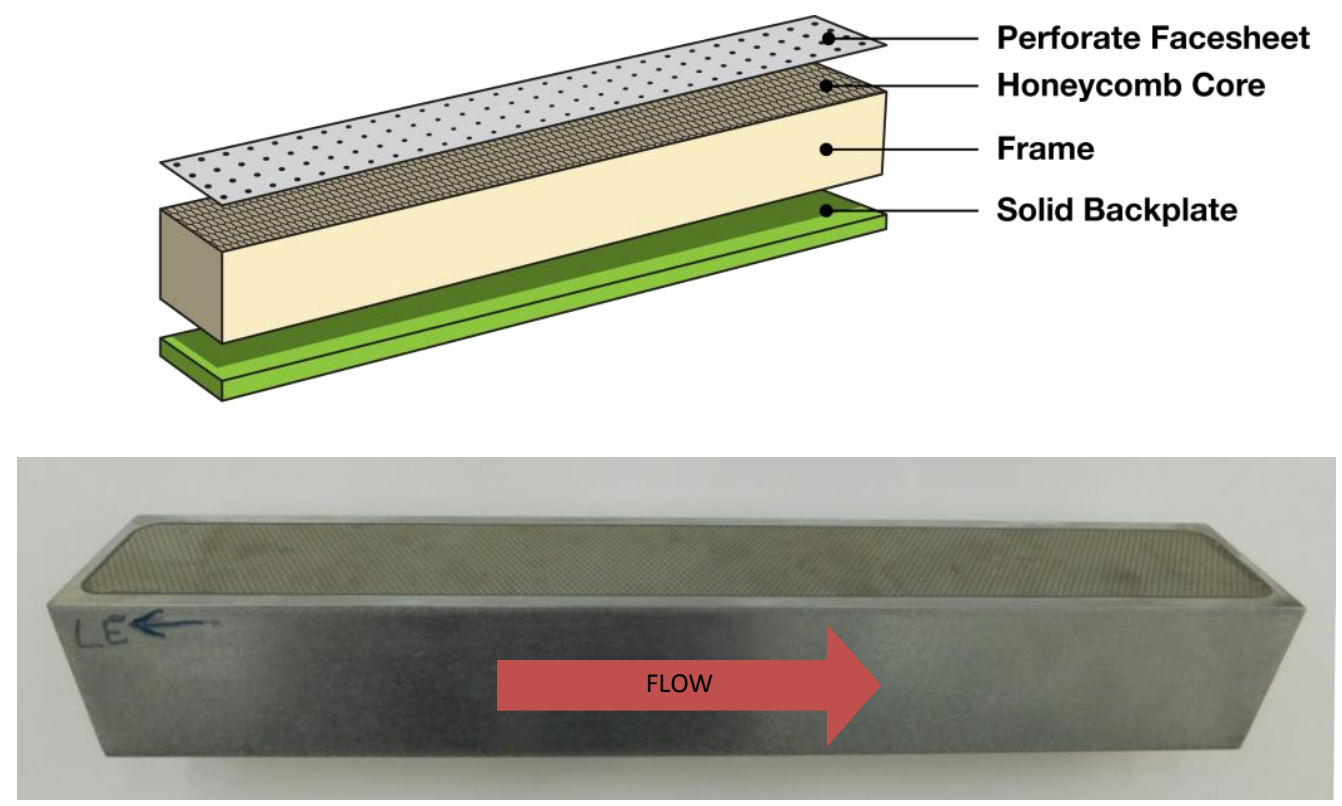

Figure 4. Typical liner sample.

\section{B. Grazing Flow Impedance Tube (GFIT)}

The GFIT is a unique facility originally constructed to determine the acoustic characteristics of noise reduction treatments (acoustic liners) for aircraft jet engine nacelles and nozzles. The facility is a small wind tunnel with a $50.8 \mathrm{~mm}$ by $63.5 \mathrm{~mm}$ rectangular cross section. The flow path (Fig. 5) is a straight duct with a 12-driver upstream acoustic source section, interchangeable lengths of blank duct, a test section holding the liner sample along the upper wall of the duct and an array of 95 measurement microphones leading to a 6-driver downstream source section and anechoic terminating diffuser. Pressurized, heated air is supplied to the entrance of the GFIT while a vacuum system is used at the duct exit to 'pull' the flow out of the tube. This arrangement allows for the static pressure at the test section to be near ambient at all flow velocities while also creating an adiabatic wall condition. In its current configuration, samples can be tested at grazing flow velocities from 0 to Mach 0.6 and sound pressure levels up to $150 \mathrm{~dB}$ for the frequency range between 400 and $3000 \mathrm{~Hz}$.

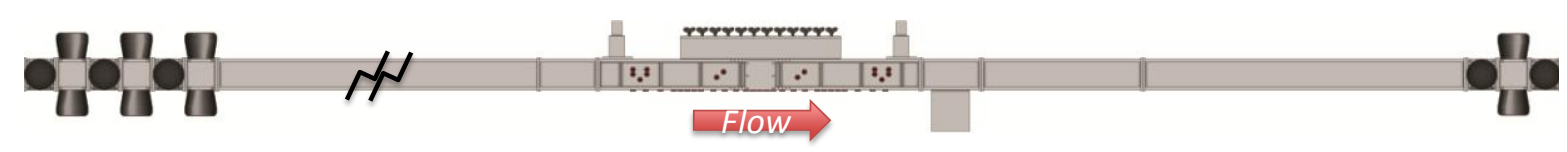

Figure 5. Sketch of the NASA Langley Grazing Flow Impedance Tube (GFIT).

This investigation also makes use of some of the 80 static pressure ports located along the lower wall of the duct to measure the axial pressure distribution. Two ports, one located near the entrance and the other located near the exit of the test section (separated axially by $1.07 \mathrm{~m}$ ) are also connected to a high-accuracy, differential pressure gauge to measure the static pressure drop between these two locations. This gauge samples at a rate of $10 \mathrm{~Hz}$ with a 0-6900 Pa range and $0.01 \%$ FS accuracy. Figure 6 is a plot of the static pressure distribution in the test section for a smooth wall configuration at $\mathrm{M}=0.5$. A sketch of the test section is included above the plot showing the relative location of the liner and the ports used to compute the static pressure drop $(\Delta \mathrm{p})$. The measurement points are designated as Port 37 and Port 59, respectively. 


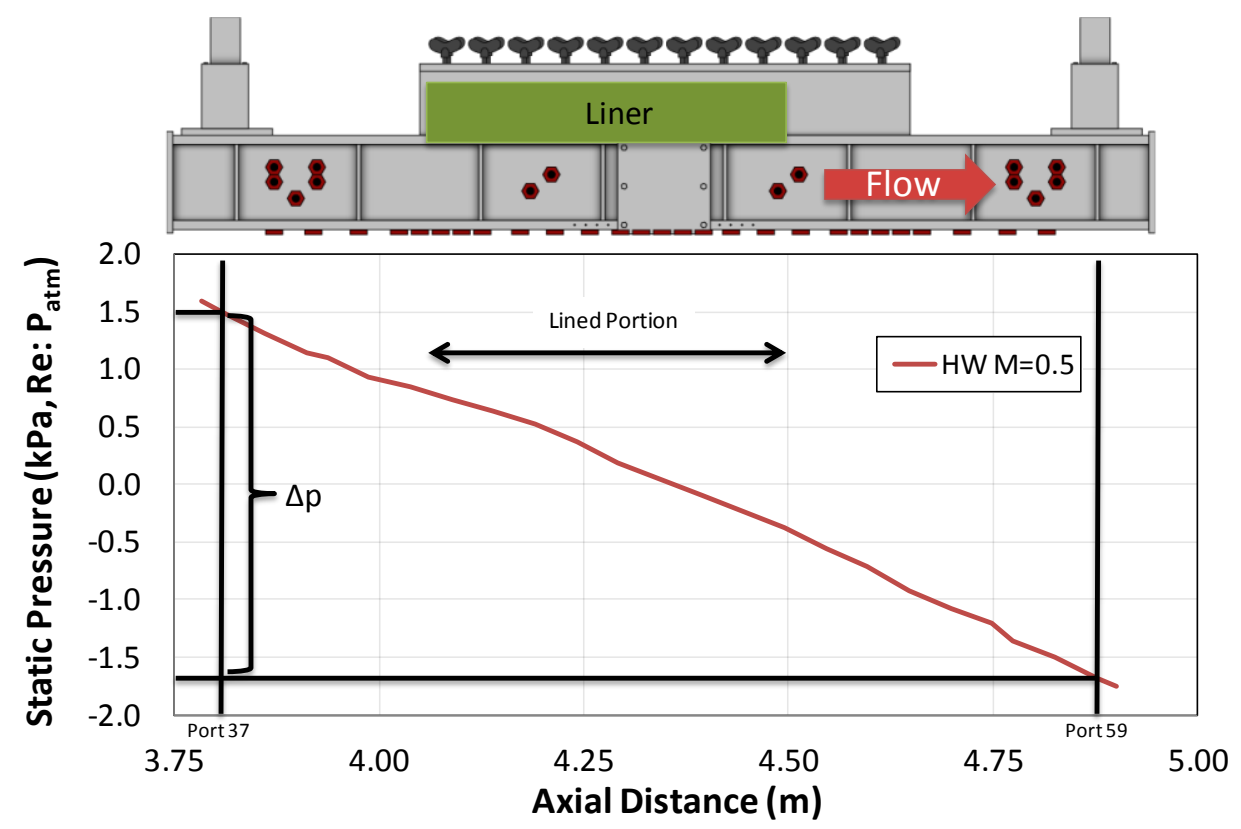

Figure 6. GFIT Test Section Static Pressure Distribution, Smooth wall sample, $M=0.5$.

\section{Measurement Process}

Following the method set forth by Howerton and $\mathrm{Jones}^{3}$, averaged static pressure measurements are made for each configuration with no acoustic excitation at $\mathrm{M}=0.3$ and 0.5 . For each data set, 300 readings are acquired from the pressure gauge to provide the static pressure drop across the length of the liner. For all cases, the target Mach number is held to a tolerance of $+/-0.002$ while static pressure in the test section is set within +/-130 Pa. Tunnel conditions, including average Mach number and static pressure, are also recorded to allow computation of $\lambda$ from Eq. (2). Use of a nondimensional coefficient like $\lambda$ provides a benefit by normalizing the static pressure data. This normalization reduces the variability of the results, allowing comparison of data from different flow runs where static pressure and Mach number differences (albeit small) can affect the raw $\Delta \mathrm{p}$ measurements. An example of this variation is shown in the left plot of Fig. 7 with a graph of $\Delta p$ measurements from the smooth wall case at nominally $\mathrm{M}=0.5$. The existence of a relationship between Mach number and $\Delta \mathrm{p}$ is readily apparent. Computation of $\lambda$ from this data results in the points shown in the right plot of Fig. 7.
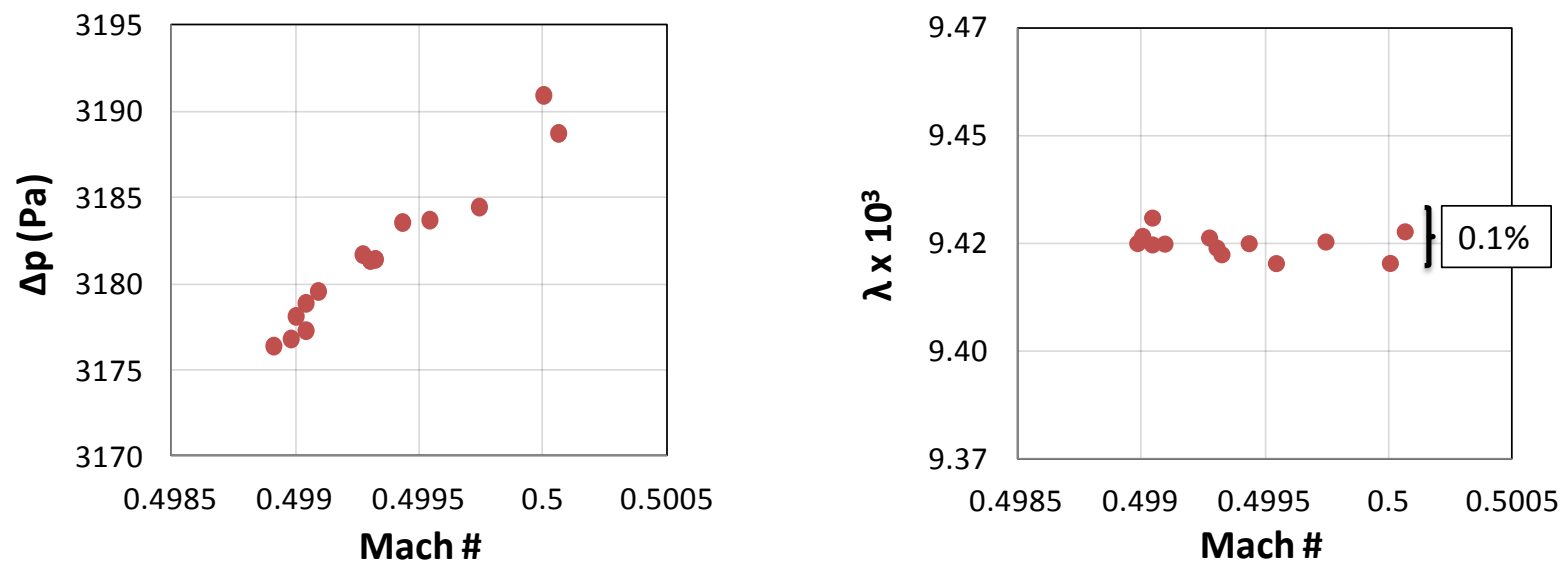

Figure 7. Liner $\Delta \mathrm{p}$ measurements and corresponding values of $\lambda$, Smooth wall sample, $M=0.5$.

The calculated values of $\lambda$ are independent of the small Mach number changes and variability of the results about the mean is nominally $0.1 \%$, indicating excellent repeatability. Comparisons with other flow speeds show variability decreasing with increasing Mach number, since $\Delta \mathrm{p}$ increases while the accuracy of the pressure gauge is fixed as a 
percentage of its range. Note that values of $\lambda$ derived from GFIT pressure measurements cannot be directly related to values of Darcy's friction factor commonly found on a Moody chart. Only a portion of the duct surface is lined and, depending upon $\mathrm{M}$ and the axial location of the test section, the flow may not be fully developed. However, correlations could be developed using samples of known roughness to provide a calibration back to absolute drag values and coefficients.

If one assumes that the contribution of each portion of the duct to the measured value of $\lambda$ is proportional to the surface area, the resistance factor of the lined portion can be determined using the following relation:

$$
\lambda_{L+S W}=\frac{P-W_{L}}{P} \lambda_{S W}+\frac{W_{L}}{P}\left(\frac{S-L L}{S} \lambda_{S W}+\frac{L L}{S} \lambda_{L}\right)
$$

where Figure 8 provides a sketch of the GFIT test section showing typical liner placement and various pertinent dimensions required to evaluate this expression.

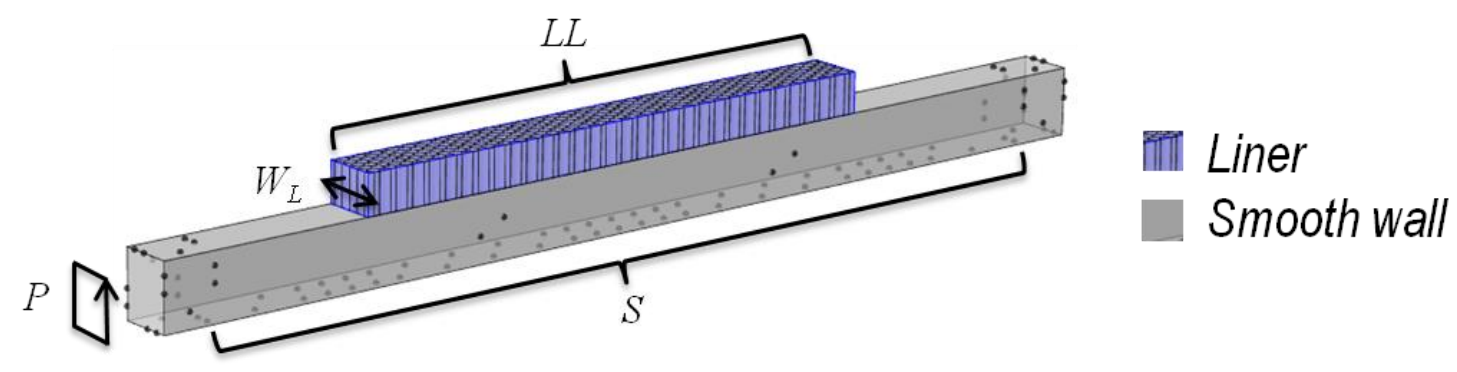

Figure 8. Sketch of GFIT test section with dimensions used for liner drag eduction.

Solving for $\lambda_{\mathrm{L}}$ gives:

$$
\lambda_{L}=\frac{\frac{P \lambda_{L+S W}-\left(P-W_{L}\right) \lambda_{S W}}{W_{L}}-\left(\frac{S-L L}{S}\right) \lambda_{S W}}{\frac{L L}{S}}
$$

In addition to the no-sound drag measurements, tonal acoustic excitation was used for $\mathrm{M}=0.3$ and $\mathrm{M}=0.5$ for frequencies between 400 and $2800 \mathrm{~Hz}$ (200 Hz increments) at a target sound pressure level (SPL) of 140 and 150 $\mathrm{dB}(\mathrm{re}: 20 \mu \mathrm{Pa})$. It is important to note that, for certain combinations of frequency and Mach number, the higher SPL was not achieved but was usually at least $6 \mathrm{~dB}$ greater than the lower target. Static pressure measurements are performed simultaneously with the acoustic surveys to evaluate the effect of acoustic excitation on liner drag. For each acoustic test point, data from the microphone array is recorded and processed using a source-referenced, crossspectral technique to compute the SPL and relative phase at the 95 microphone locations. Acoustic measurements are performed to allow for comparison of liner impedances educed from this data using the Straightforward Method of Watson? ${ }^{7}$.

\section{Results and Discussion}

\section{A. Static Pressure Measurements}

Figure 9 shows the liner resistance factor $\left(\lambda_{\mathrm{L}}\right.$, computed from Eq. (6)) for the smooth wall and nine liner configurations tested at Mach numbers of 0.3 and 0.5 with no sound. 


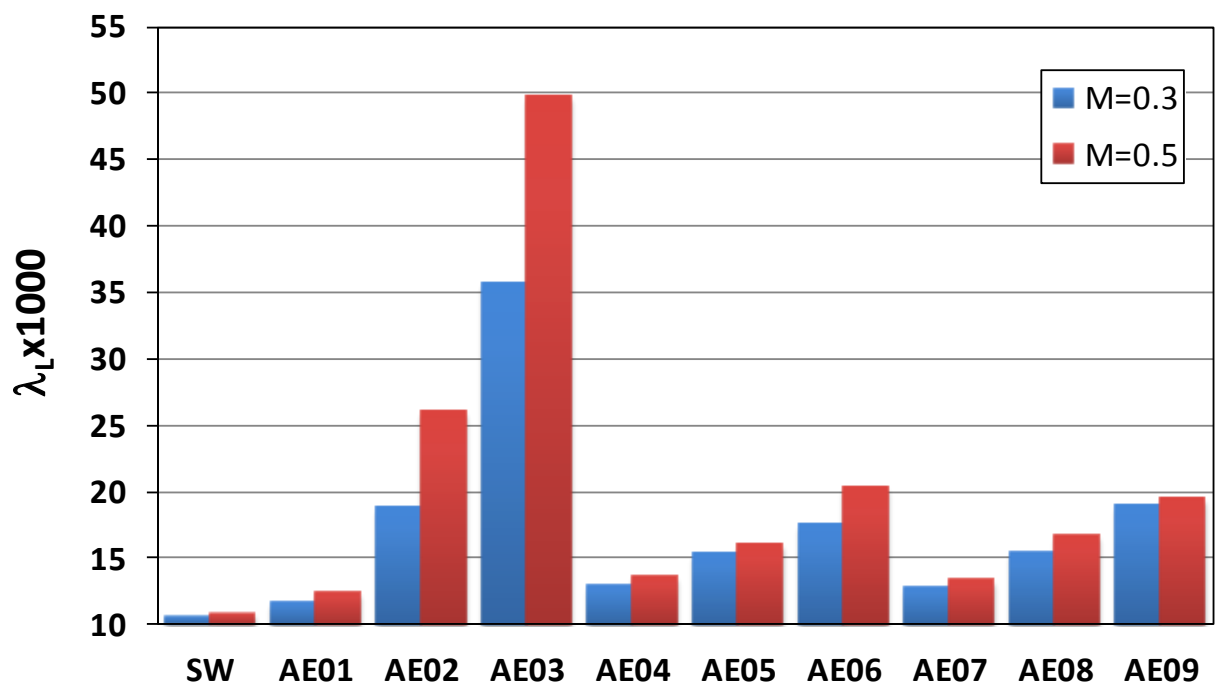

Figure 9. Liner resistance factor $\left(\lambda_{L}\right) \times 1000$ for $M=0.3$ and 0.5 , no sound.

For all cases, $\lambda_{\mathrm{L}}$ increases with increasing Mach number and all configurations produce a drag penalty relative to the SW. Within the groups of liners with a common underlayment configuration (i.e., AE01-03 - no underlayment), increasing POA results in increased values of $\lambda_{\mathrm{L}}$. Adding the mesh reduces the resistance factor by approximately $50 \%$ for the 30 POA samples (AE03 vs AE06, AE09) while the lower POA samples do not see as great a benefit. A previous study by the authors found that reducing the perforate hole size generally reduced the measured $\lambda_{\mathrm{L}}$. The comparison of AE04 with AE07 does follow the expected trend. This effect is not clearly observed, however, when comparing AE05 with AE08. Both configurations have the same POA, but AE08 has smaller holes as well as a more resistive underlayment which should lower the resistance factor.

\section{B. Effects of Acoustic Excitation on Drag}

Each liner configuration was evaluated in the presence of acoustic tonal excitation at target total SPLs of 140 and $150 \mathrm{~dB}$. Frequencies ranged from $400 \mathrm{~Hz}$ to $3000 \mathrm{~Hz}$, in $200 \mathrm{~Hz}$ increments. It was postulated prior to the test that the oscillatory motion of fluid through the facesheet perforations would affect the measured resistance factor. Expectations of significant variation in $\lambda_{\mathrm{L}}$ at or near the frequencies of resonance $(\sim 1200-1600 \mathrm{~Hz}$ for these configurations) and antiresonance were also postulated. Figure 10 shows resistance factor spectra for the two Mach numbers and SPLs. Several trends emerge from these plots. The resistance factor of the liner can vary with frequency. The variation increases with increasing SPL and decreases with increasing Mach number. A significant change in the resistance factor does occur near resonance for liners AE02, AE03 and, to a lesser degree, AE06. The other configurations do not exhibit this behavior, however. This result seems to at least partially confirm the aforementioned hypothesis for reasons to be discussed later. For flow speeds of Mach 0.5, even the $150 \mathrm{~dB}$ level results in variations only on the order of $10-15 \%$, significantly less than that observed for the Mach 0.3 cases. A notable feature of the spectra is the dip in many of the $150 \mathrm{~dB}$ results at $1200 \mathrm{~Hz}$ and is most readily apparent in the $\mathrm{M}=0.3$ results. The current GFIT acoustic speaker array and anechoic terminations seem to be inefficient at transmitting acoustic energy from the loudspeakers into the duct, thus limiting the maximum SPL at that frequency to approximately $141 \mathrm{~dB}$. This level is substantially less than that achieved at other test frequencies and, as a result, produces a diminished effect on the liner resistance factor.

Figure 11 replots the $\mathrm{M}=0.5$ results with the AE03 trace omitted in order to focus on the other eight configurations. One can see clustering of the plots into distinct groups indicating that some liner parameter or acoustic characteristic may be responsible for the grouping. The bottom cluster corresponds to liners AE01, AE04 and AE07, which all have the minimum POA value of 10. This trend is consistent with previous experiments performed by the authors. The next two clusters also group by POA indicating that this parameter may be one of the more dominant ones in determining the liner drag. The upper spectra for AE02 should, theoretically, group with the spectra for AE07 and AE08 based on their common 20 POA. The shift upward may be explained by the hole size for 
AE02 which, at $1.78 \mathrm{~mm}$, is the largest of the three and the fact that AE02 has no mesh underlayment. The effect of this larger hole size (which has the tendency to increase drag) may be overwhelming the influence of POA.

\section{$\mathbf{M}=\mathbf{0 . 3}$}
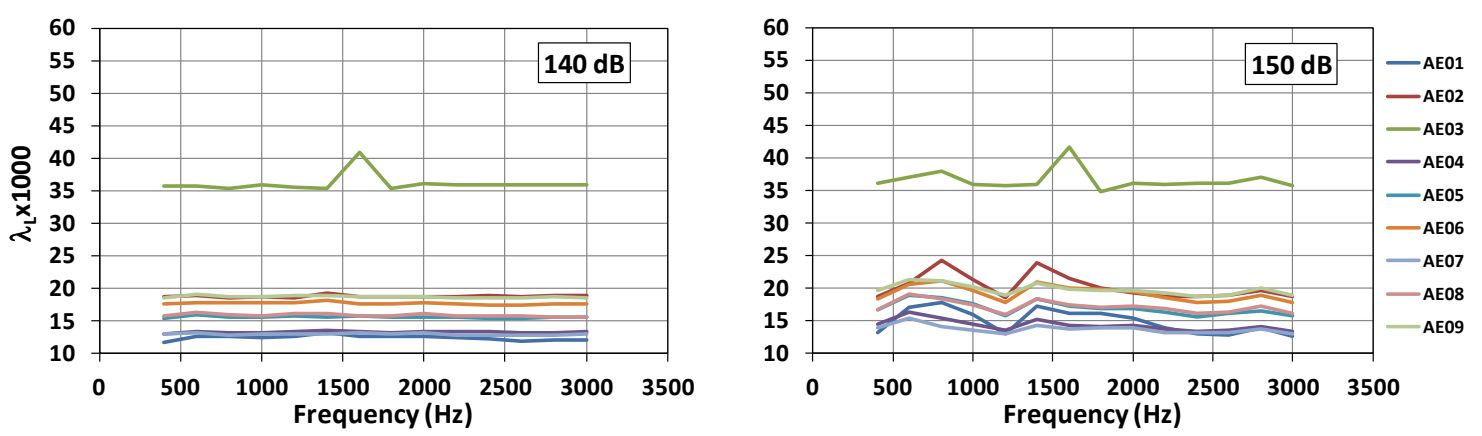

\section{$\mathrm{M}=\mathbf{0 . 5}$}
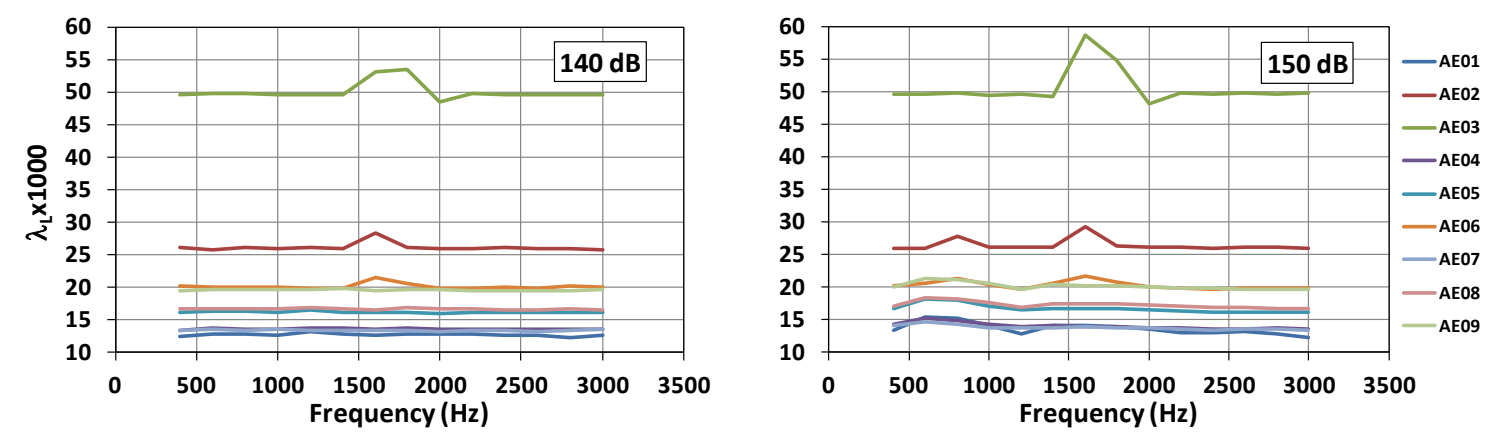

Figure 10. Variation of resistance factor with acoustic excitation.

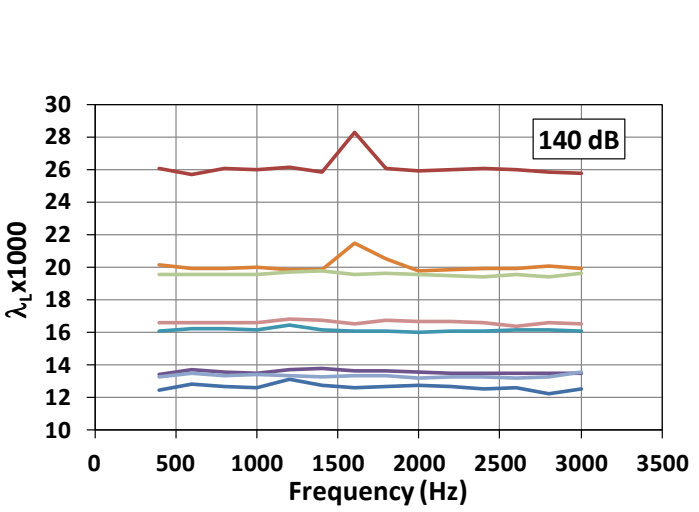

\section{$\mathrm{M}=\mathbf{0 . 5}$}

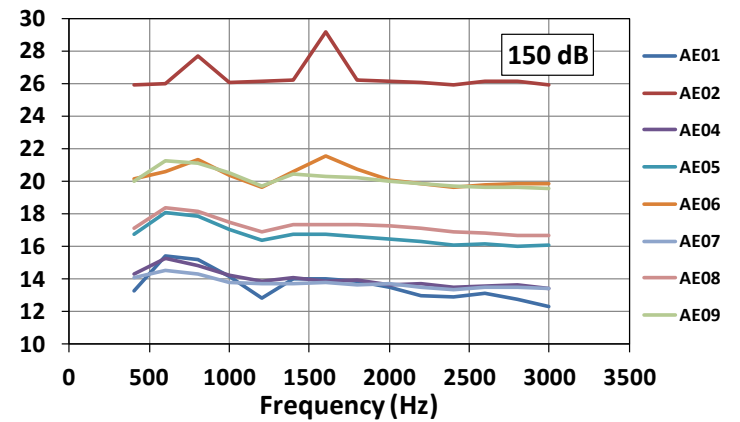

Figure 11. Variation of resistance factor with acoustic excitation (excluding AE03).

\section{Acoustic Measurements}

For each liner configuration, full acoustic pressure profiles were acquired at $\mathrm{M}=0.3$ and 0.5 for the purposes of impedance eduction and evaluation of attenuation performance. As noted before, there are certain frequencies where $150 \mathrm{~dB}$ was not achieved, but at least $145 \mathrm{~dB}$ is achieved for the majority of those cases. These educed impedance spectra are compared to determine variations in liner acoustic performance relative to the parameters of the liner configuration. 
Figures 12-21 show the normalized impedance spectra (all impedances are normalized by $\rho c$ ) for each configuration for $\mathrm{M}=0.5$ at 140 and $150 \mathrm{~dB}$. The effect of increasing the SPL on the educed impedances is minimal for all configurations. The general shape of the spectra are similar for all cases save for AE04 and AE07, which have the minimal POA and a mesh underlayment driving their resistances significantly higher. As stated earlier, resonance varies between 1200 and $1600 \mathrm{~Hz}$ with many configurations showing signs of an upcoming antiresonance at the upper end of the frequency range. Adding the mesh increases resistances over the no-mesh configurations, but the amount of increase for AE04 and AE07 is much greater than the resistance values of the underlayment. This result warrants further study and can be a useful phenomena to exploit if the underlying physics are understood.
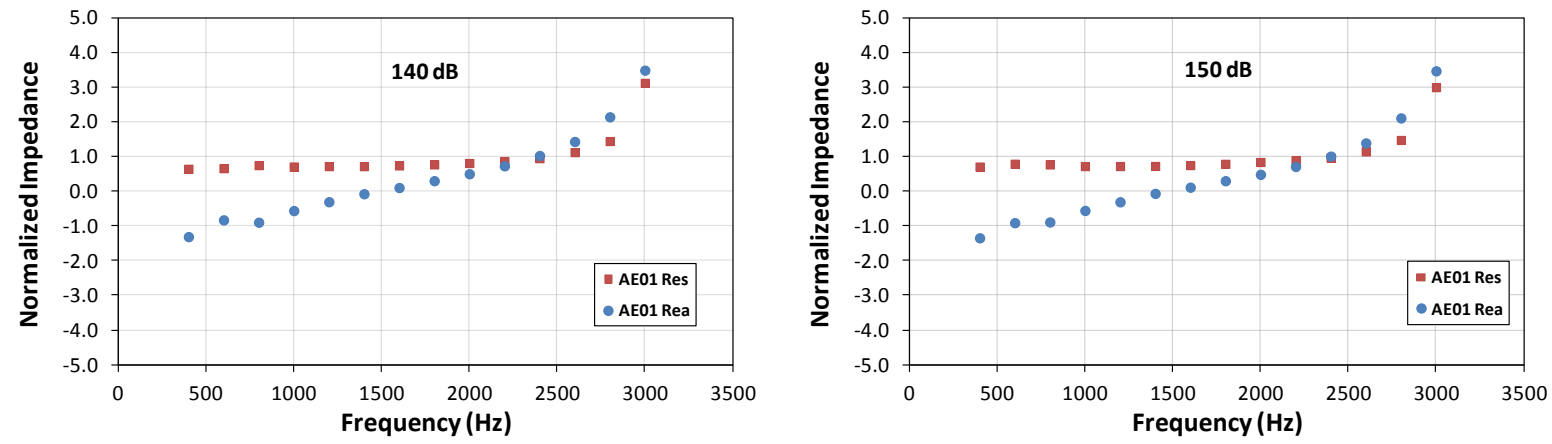

Figure 12. Normalized impedance spectra for $\mathrm{AE01,} M=0.5$.
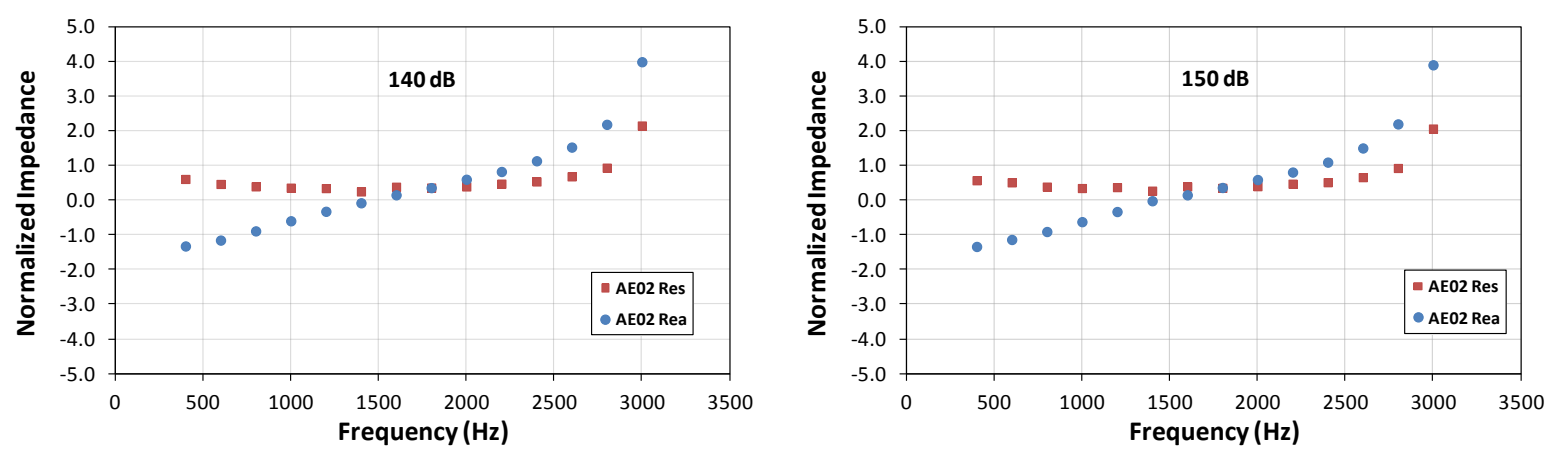

Figure 13. Normalized impedance spectra for AE02, $M=0.5$.
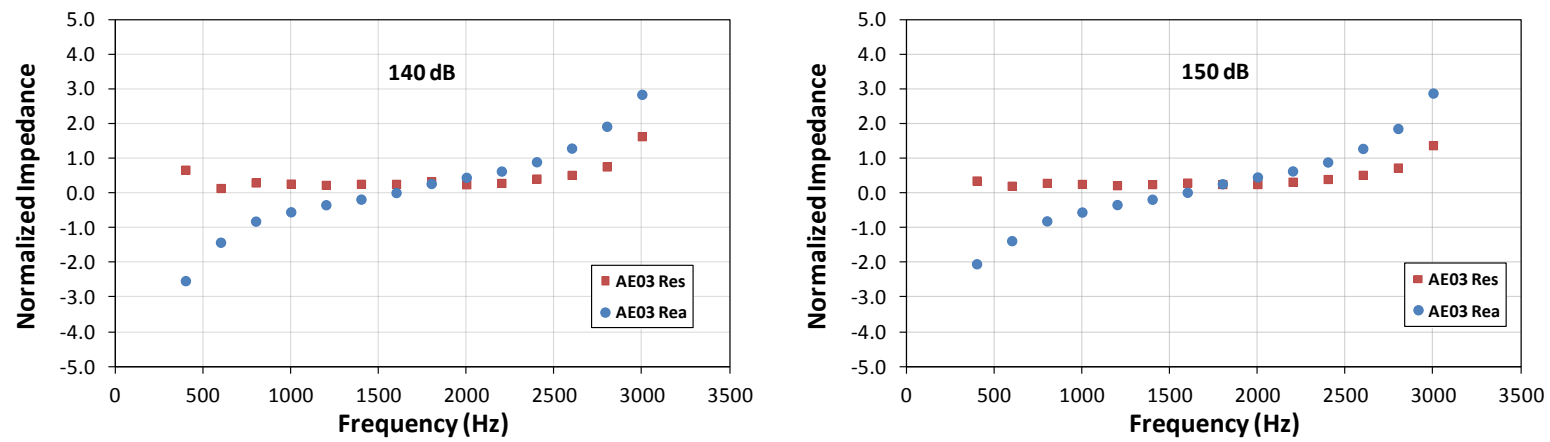

Figure 14. Normalized impedance spectra for $\mathrm{AE03,} M=0.5$.

10

American Institute of Aeronautics and Astronautics 

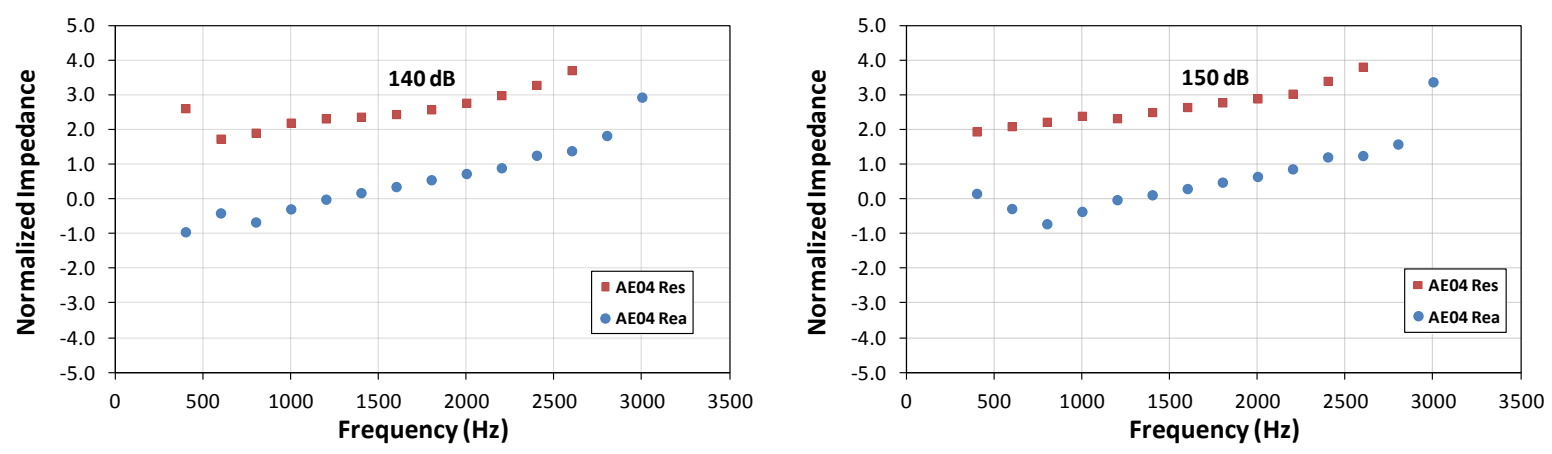

Figure 15. Normalized impedance spectra for AE04, $M=0.5$.
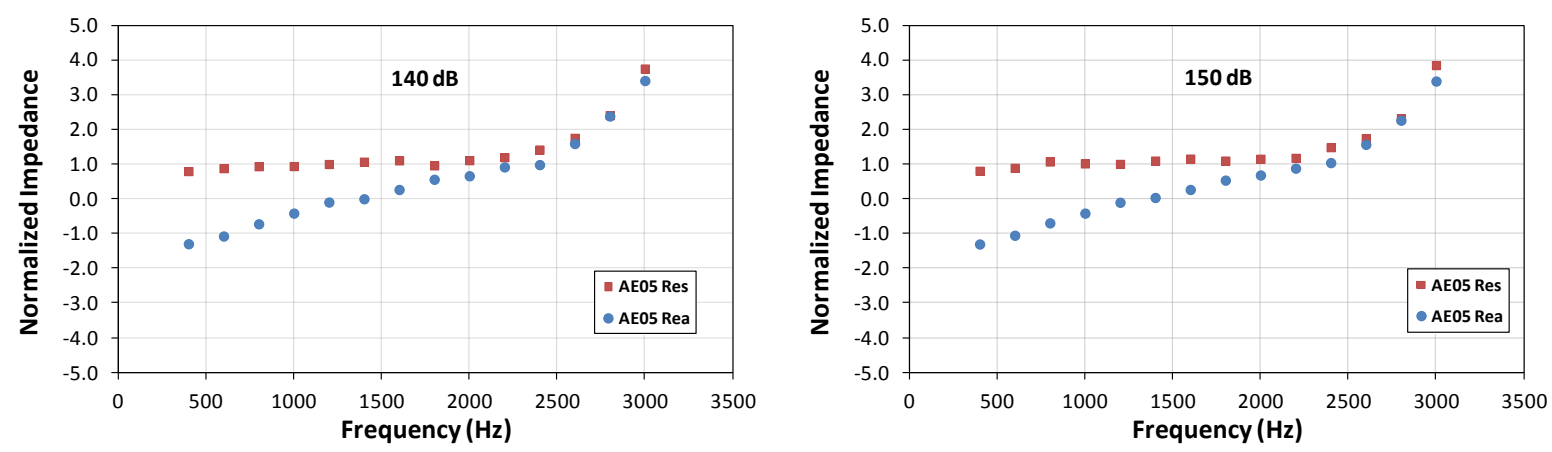

Figure 16. Normalized impedance spectra for $\mathrm{AE05}, \mathrm{M}=0.5$.
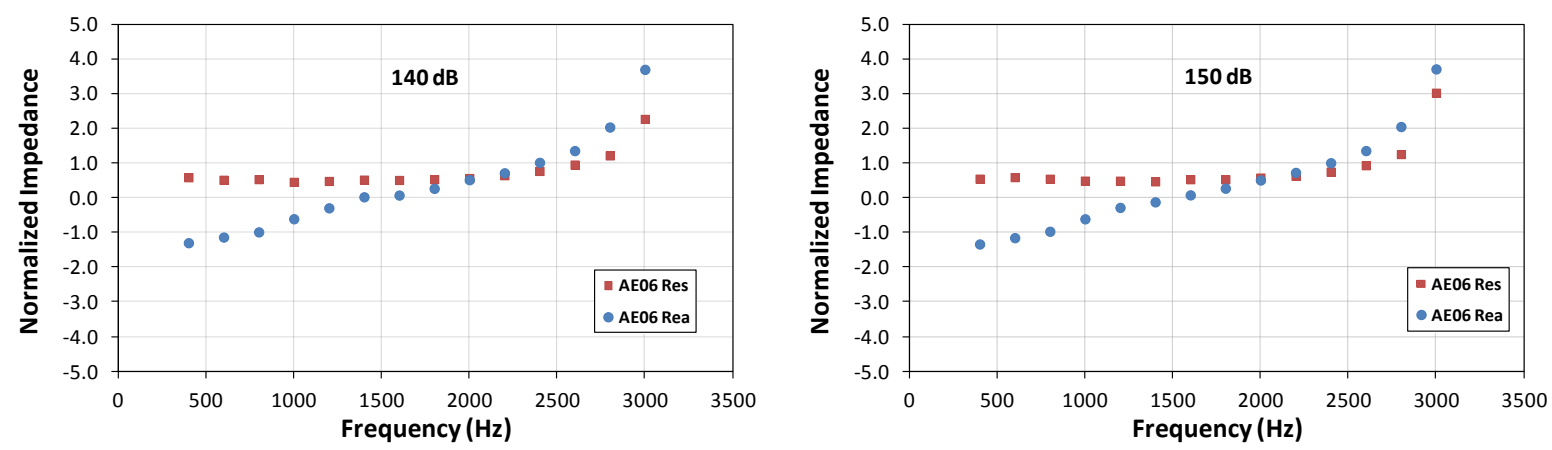

Figure 17. Normalized impedance spectra for AE06, $M=0.5$.

11

American Institute of Aeronautics and Astronautics 

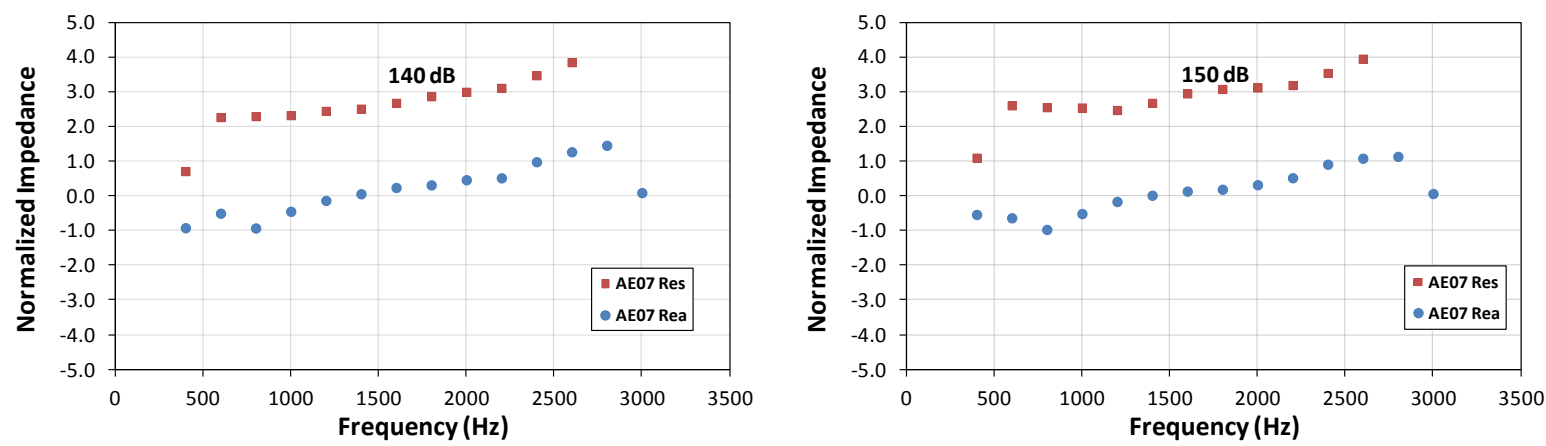

Figure 18. Normalized impedance spectra for $\mathrm{AE07}, \mathrm{M}=\mathbf{0 . 5}$.
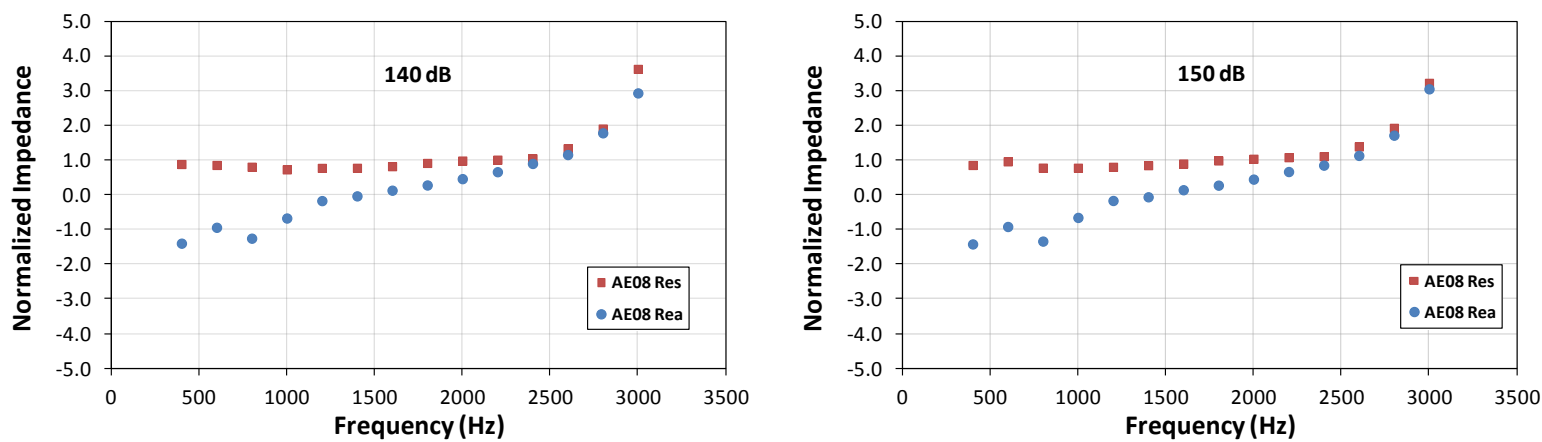

Figure 19. Normalized impedance spectra for $\mathrm{AE08,} M=0.5$.
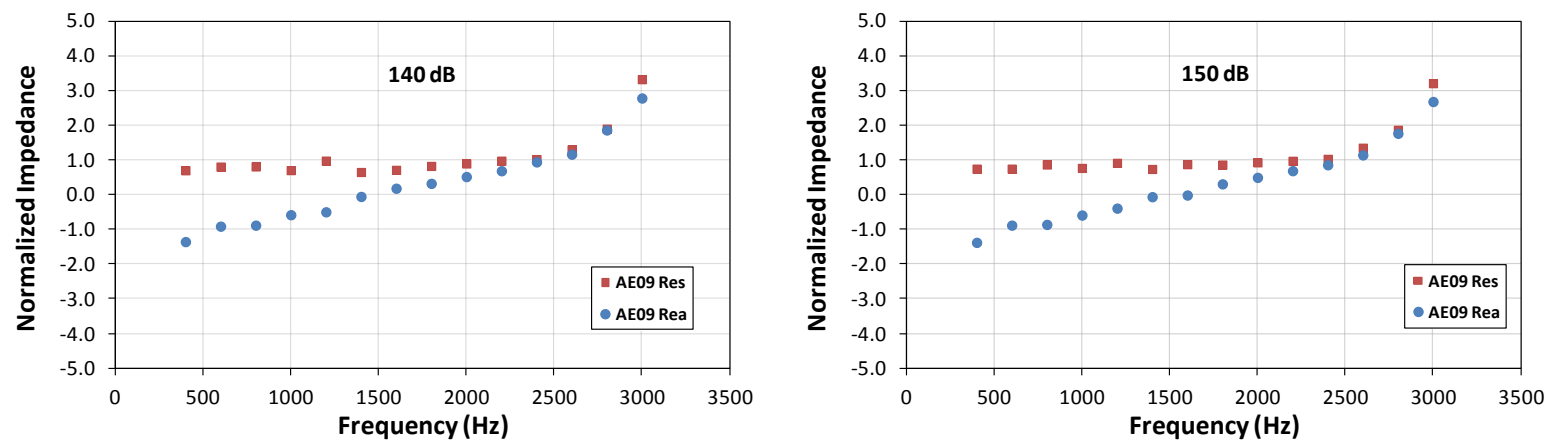

Figure 20. Normalized impedance spectra for AE09, M=0.5.

12

American Institute of Aeronautics and Astronautics 

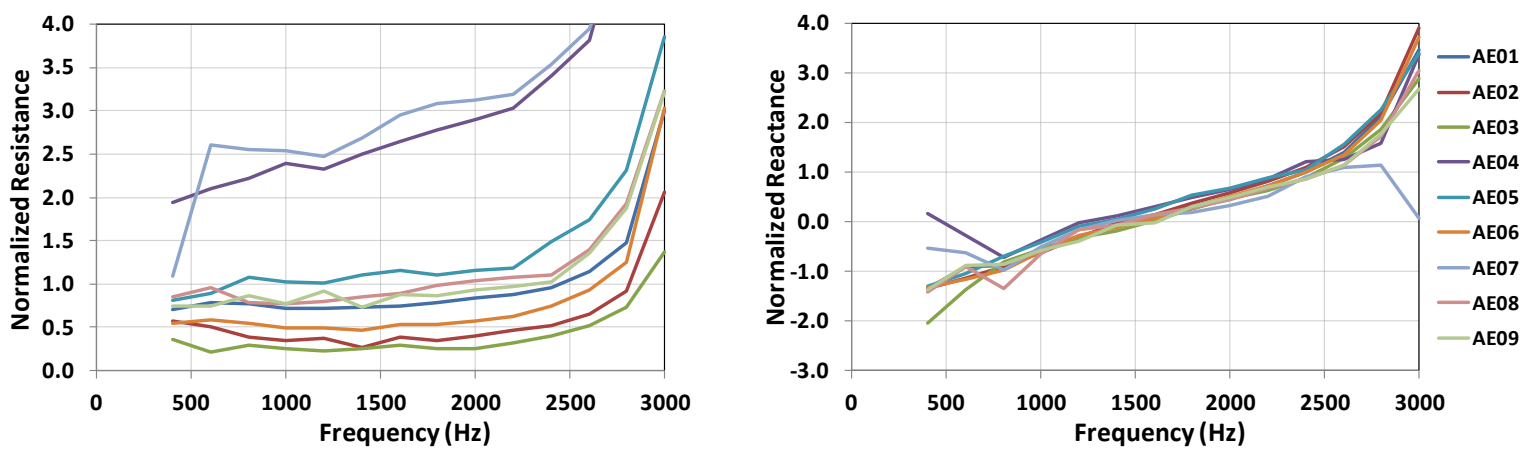

Figure 21. Comparison of impedance spectra, $M=0.5,150 \mathrm{~dB}$.

Figure 21 combines all the impedance spectra for each configuration for the case of $\mathrm{M}=0.5$ and $150 \mathrm{~dB}$ excitation. Immediately, it is obvious that AE04 and AE07 have much higher values for resistance than the other configurations, which are in a band nominally between 0.25 and $1.0 \rho c$. Liners with higher POA values generally have lower resistance values but the mesh underlayment does shift the curves upward relative to those without mesh.

Another method of evaluating liner performance is to compare the levels of attenuation achieved by the various configurations. This calculation gives a gross estimate of the effect these variations in perforate geometry have on the overall acoustic performance of the liner.

Figure 22 gives results of a simple attenuation estimate calculated using the difference in sound pressure levels measured at the leading and trailing edges of the duct $(203.2 \mathrm{~mm}$ upstream of liner leading edge and $355.6 \mathrm{~mm}$ downstream of liner trailing edge, respectively). Such a result does include the effects of reflections from these edges and the influence of the duct termination. However, it provides a useful quantity for comparison. Points of a common symbol type have the same perforate underlayment while points of a common color have the same POA value. For the lowest frequencies below $1 \mathrm{kHz}$ and the highest above $2 \mathrm{kHz}$, the measured attenuation shows little variation regardless of POA or underlayment. The differences between configurations become more apparent in the data centered around $1.4 \mathrm{kHz}$. One observes relatively low attenuation for the 10 POA samples with mesh while the more porous samples like AE03 and AE06 perform much better.

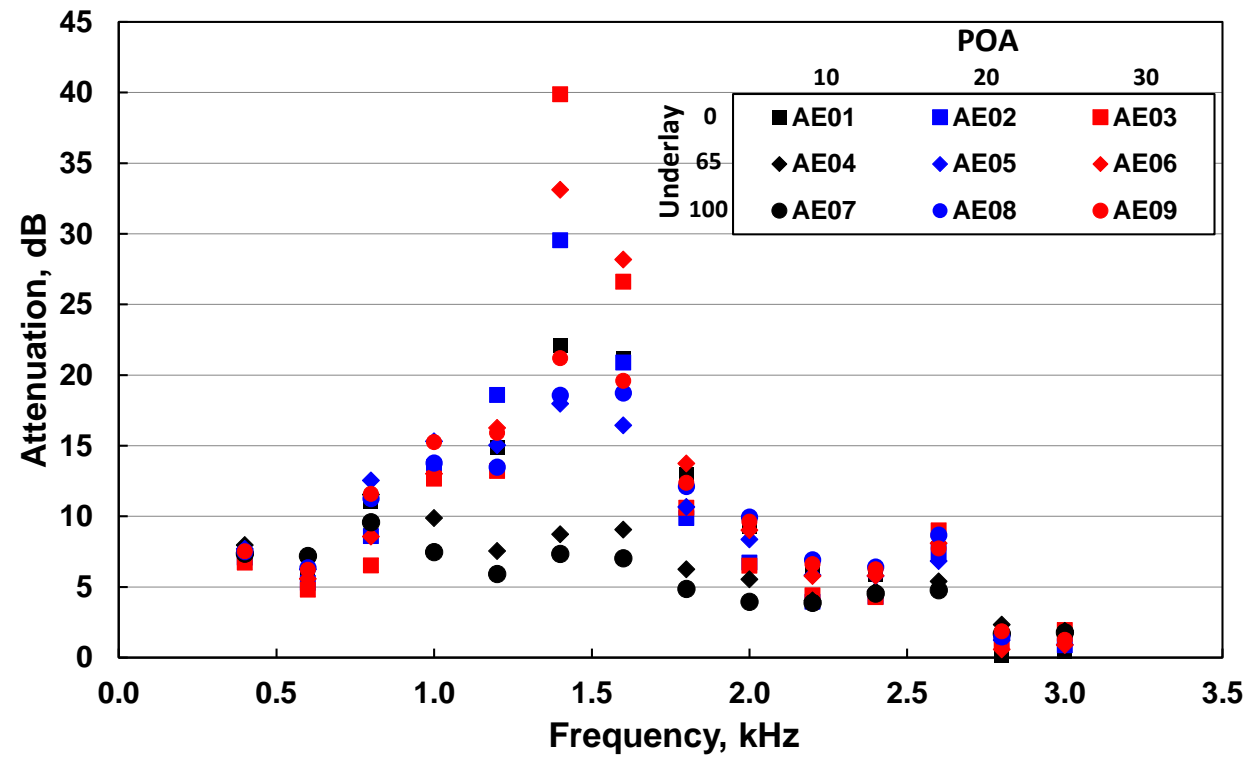

Figure 22. Liner attenuation spectra, $M=0.5,140 \mathrm{~dB}$. 


\section{Acoustic/Drag Interactions}

This section will focus on observations related to the measured liner resistance factors as they relate to the acoustic impedance spectra. Results have shown trends relating drag and frequency variations in resistance factor to normalized resistance as seen in Figure 23. One readily apparent observation is that high acoustic resistance values can be correlated to lower drag values as seen for AE04 and AE07. Acoustic measurements from AE03 produced the lowest values for normalized resistance across the frequency range while simultaneously having the highest values for $\lambda_{\mathrm{L}}$. In general, the higher the normalized resistance values for the liner, the lower the resistance factor measured.
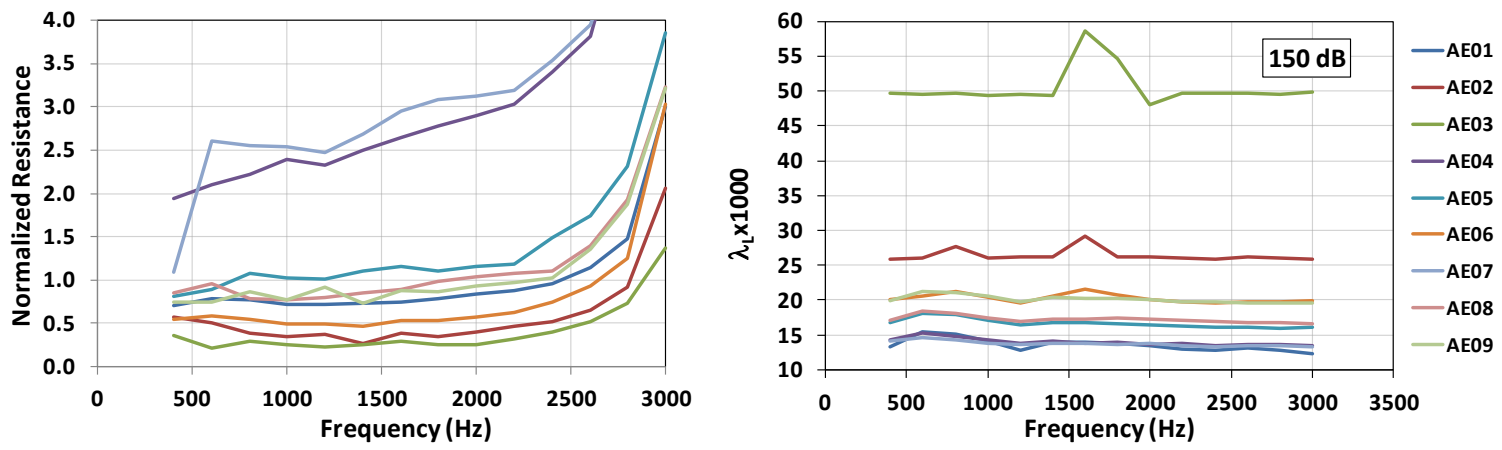

Figure 23. Comparison of normalized impedance spectra and the corresponding $\lambda_{\mathrm{L}}$ for all liners, $M=0.5$, $150 \mathrm{~dB}$.

\section{Concluding Remarks}

Measurements of liner resistance factors were made for nine liner configurations with various combinations of POA, hole size and mesh underlayment resistances for flow Mach numbers of 0.3 and 0.5 . The effects of acoustic excitation on $\lambda_{\mathrm{L}}$ for two sound pressure levels were also investigated. Analysis of the acoustic data was performed to educe liner impedance spectra, which was compared to the drag data in an effort to understand general trends related to conventional liner designs. Several observations were noted:

1. Percent open area (POA) is a significant first order effect on liner drag and couples closely with normalized resistance. Generally, higher POA liners exhibited lower normalized resistance and higher $\lambda_{\mathrm{L}}$.

2. The addition of mesh underlayment lowered the observed $\lambda_{\mathrm{L}}$ for liners with the same POA although the effect on $\lambda_{\mathrm{L}}$ of increasing the mesh resistance from 65 to 100 MKS Rayls was minimal.

3. The effects of acoustic excitation on the measured resistance factors were more apparent for lower Mach numbers, higher sound pressure levels and near the liner resonant frequency. The increase in $\lambda_{\mathrm{L}}$ near resonance is greatest for liner configurations where the normalized resistance is less than $0.5 \rho c$.

4. Liner reactance spectra were similar for all configurations tested even with the significant parametric variation between liner facesheets.

5. Liners with higher measured normalized resistance values tend to have lower measured $\lambda_{\mathrm{L}}$ values. The higher resistance has the general effect of reducing attenuation, as measured in the GFIT, especially near the liner's resonant frequency. Conversely, liners with lower measured normalized resistance values tend to have higher measured $\lambda_{\mathrm{L}}$ values and increased attenuation near resonance.

Further analysis could be performed on this data using statistical methods to rank order the importance of each liner parameter on $\lambda_{\mathrm{L}}$. This information would be useful in making design trades to balance acoustic absorption performance with liner drag. 


\section{Acknowledgments}

The authors would like to thank Carol Harrison of the NASA Langley Structural Acoustics Branch for her efforts in collecting the experimental data. Funding for this effort was provided under the NASA Advanced Air Transport Technology Project for the Advanced Air Vehicles Program and by the Environmentally Responsible Aviation Project for the Integrated Aviation Systems Program.

\section{References}

${ }^{1}$ Tam, Christopher K. W., Pastouchenko, Nikolai N., Jones, Michael G., Watson, Willie R., "Experimental Validation of Numerical Simulations for an Acoustic Liner in Grazing Flow," AIAA Paper 2013-2222, 19 ${ }^{\text {th }}$ AIAA/CEAS Aeroacoustics Conference, May 2013.

${ }^{2}$ Drouin, M. K.,Gallman, J. M., and Olsen, R.F., "Sound Level Effect on Perforated Panel Boundary Layer Growth," AIAA Paper 2006-2411, May 2006

${ }^{3}$ Howerton, Brian M., and Jones, Michael G., "Acoustic Liner Drag: Measurements on Novel Facesheet Perforate Geometries," AIAA Paper 2016-2979, 22 ${ }^{\text {nd }}$ AIAA/CEAS Aeroacoustics Conference, June 2016.

${ }^{4}$ Thomas, R. H., Burley, C. L., Lopes, L. V., Bahr, C. J., Gern, F. H. and Van Zante, D. E., "System Noise Assessment and the Potential for a Low Noise Hybrid Wing Body Aircraft with Open Rotor Propulsion," AIAA Paper 2014-0258, January 2014.

${ }^{5}$ Nikuradse, J., "Laws of Flow in Rough Pipes," NACA TM-1292, November 1950.

${ }^{6}$ Howerton, Brian M., and Jones, Michael G., "Acoustic Liner Drag: A Parametric Study of Conventional Configurations," AIAA Paper 2015-2230, $21^{\text {st }}$ AIAA/CEAS Aeroacoustics Conference, AIAA Aviation 2015, June 2015.

${ }^{7}$ Watson, W. R., and Jones, M. G., "A Comparative Study of Four Impedance Eduction Methodologies Using Several Test Liners,” AIAA Paper 2013-2274, 19 ${ }^{\text {th }}$ AIAA/CEAS Aeroacoustics Conference, May 2013. 